\title{
Water resources management in southern Europe: Clues for a research and innovation based regional hypercluster
}

\author{
G. Martins $^{\mathrm{a}, *}$, A.G. Brito ${ }^{\mathrm{a}}$, R. Nogueira ${ }^{\mathrm{a}, 1}$, M. Ureña $^{\mathrm{b}}$, D. Fernández ${ }^{\mathrm{b}}$, F.J. Luque $^{\mathrm{b}}$, C. Alcácer ${ }^{\mathrm{b}}$ \\ ${ }^{a}$ IBB - Institute for Biotechnology and Bioengineering, Centre of Biological Engineering, University of Minho, Campus de Gualtar, 4710-057 Braga, Portugal \\ ${ }^{\mathrm{b}}$ CENTA - Centre for the New Water Technologies, Autovía Sevilla-Huelva (A-49), km 28, 41820 Carrión de los Céspedes, Sevilla, Spain
}

\section{A R T I C L E I N F O}

\section{Article history:}

Received 30 July 2012

Received in revised form

11 January 2013

Accepted 29 January 2013

Available online

\section{Keywords:}

NOVIWAM

Water resources

Innovation

Research

Governance

\begin{abstract}
A B S T R A C T
European countries are facing increasing pressures on their water resources despite stringent regulations and systematic efforts on environmental protection. In this context, research and innovation play a strategic role reinforcing the efficiency of water policies. The present study provides a multilevel assessment of research and innovation practices in the field of water resource management in southern European countries and regions (more specifically; Cyprus, Albania, Poitou-Charentes in France, Andalusia in Spain and the North of Portugal). The analysis was based on a strategic framework aimed at gaining an insight of the current constraints, as well as of the existing and future technological solutions for a better water resource management. The triple helix model proved to be a useful analytical framework for assessing the efforts of different groups towards a common goal. The analysis proved the existence of a significant evolution in the use of technological tools to assist decision-making processes in integrated river basin management in all regions. Nevertheless, the absence of formal channels for knowledge and data exchange between researchers and water resource managers complicates the formers involvement in the decision-making process regarding water allocation. Both researchers and consultants emphasize the low availability of data, together with the need to advance on water resource economics as relevant constraints in the field. The SWOT analysis showed similar concerns among the participating regions and provided a battery of effective projects that resulted in the preparation of a Joint Action Plan.
\end{abstract}

(c) 2013 Elsevier Ltd. All rights reserved.

\section{Introduction and objectives}

Water is increasingly becoming a limiting factor for development and sustainable economic growth. In that context, the Water Framework Directive - WFD (European Community, 2000) reinforced the environmental perspective of water resources management goals in Europe, aiming the aquatic ecosystems protection and rehabilitation, and integrated planning (Pahl-Wostl et al., 2010). The WFD was an effective response to the existing concern about the weak sustainability of the business-as-usual approach to water resources management (García-Ruiz et al., 2011). Urban growth, as well as food and energy demands and recreational activities, are some of the steadily increasing pressures over water resources (Dinar, 2012; Cudennec et al., 2007). This is the case in

\footnotetext{
* Corresponding author. Tel.: +351 253604412; fax: +351 253604429 .

E-mail address: gilberto.martins@deb.uminho.pt (G. Martins).

1 Present address: Institute of Sanitary Engineering and Waste Management, University of Hannover, Welfengarten 1, D-30167 Hannover, Germany.
}

the Mediterranean basin, where an uneven distribution of water in space and time is the main feature of the hydrological regime (López-Moreno et al., 2011). Furthermore, several regions are below the UNDP indicator of water stress $\left(1000 \mathrm{~m}^{3}\right.$ capita $^{-1}$ year $\left.^{-1}\right)$ and the renewable resource exploitation index is over $25 \%$ in several regions (Plan Bleu, 2011). In combination with an increased water demand, the negative trends on droughts and floods will worsen in the future, according to all climate change scenarios regarding Southern European countries (Ferrer et al., 2012; Milly et al., 2005).

Sustainable river basin management requires increased levels of integration between users, water managers, planners and policy makers and scientists across spatial scales (Macleod et al., 2007). In addition, previous authors highlighted the importance of a careful analysis of the water governance system, its actors, interests, values, and processes (Miranda et al., 2011). Therefore, an interregional and multilevel cooperation, aiming at sharing innovative water management tools for attaining WFD goals is envisaged. By learning by sharing experiences and pooling the related science and know-how, the capacity to address water problems would increase and new innovative solutions should be achieved. 
As a matter of fact, the exchange of knowledge and innovation amongst water stakeholders is rather difficult (Huntjens et al., 2011). The reason being not only market competition but the lack of a good governance model also. Innovative solutions to water related challenges can directly support wider environmental objectives such as protecting our natural assets and ecosystems, and the biodiversity that supports them, but regional water clusters remain fragmented and do not work on creating a trans-national water hypercluster involving public administration, research and industry (EIP, 2012). This new concept of water hypercluster is based on the approach presented in Lopes (2009) and designates a set of clusters that do not necessarily have economic or technological exchanges amongst themselves but are linked to a common resource carrying out similar functions and activities. In the case in hand, the common resource is water and an organized platform and collective strategy aiming at optimizing its value does not exist at such a territorial level. Therefore, the objective of the present study was to evaluate research and interaction strategies for innovation advancement in regions in the south of Europe.

This study was carried out as part of the project Novel Integrated Water Management Systems for Southern Europe (NOVIWAM), launched under the EU's 7th Framework Program of Research and Technological Development (FP7) within the Regions of Knowledge (RoK) Initiative. The NOVIWAN project involves entities from five territories from southern Europe: the North of Portugal, Andalusia in Spain, Poitou-Charentes in France, Albania and Cyprus, and includes representations from public administration, research and business. The main goals of the project are to facilitate cooperation between authorities, research, and business of each regional cluster, to become a wide international research driven network of clusters focused on water and to develop a research agenda proposing solutions to the needs identified in the participating regions. To achieve this, the project carried out an intensive characterization of the participating regions, concluding in a SWOT analysis, that served as drafting basis for the development of the NOVIWAM Joint Action Plan (JAP), which includes a series of actions to be undertaken and promoted jointly by the participants aimed at addressing the issues identified in the SWOT, using the internal strengths and external opportunities to correct the detected weaknesses and be ready to face potential threats.

\section{Identification of NOVIWAM involved regions}

The consortium consists of five regional research driven clusters (Fig. 1), from the following regions: North of Portugal, Andalusia (Spain), Poitou-Charentes (France), Albania and Cyprus.

These five NOVIWAM regions are located principally in areas with a "subtropical dry summer", humid subtropical or humid oceanic climate (European climate zone). These different climatic conditions lead to different water usages, but are very interesting to study in the perspective of the European WFD, since they lead to similar problems of water scarcity and water quality. In Table 1 it is presented a summary of main figures numbers in terms of precipitation and water demands for each region.

In Cyprus and Andalusia, the harsh hydrological conditions faced, i.e. limited water resources combined with droughts and desertification problems and a continuous increase in the water demand, amplified the importance of a proper integrated and sustainable water management. In other side, Poitou-Charentes, North of Portugal and Albania in a lesser extent, may be seen by other Mediterranean countries as regions rather well-off concerning water availability (Table 1) (Sidibé et al., 2011).

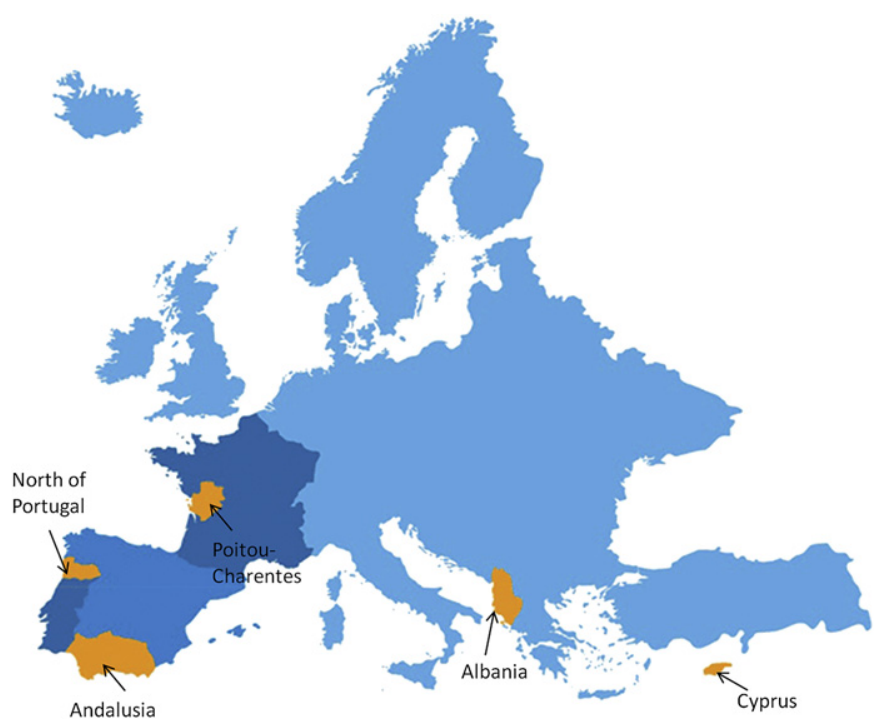

Fig. 1. Location of the NOVIWAM regions.

\section{Methodology}

The conceptual approach for the evaluation of research and interaction strategies for the advancement of innovation was based on the so-called Triple Helix Model (THM) as presented by Etzkowitz and Ranga (2010). The THM is based on the networking of public administration with research centres and business companies in research driven clusters that have a central role in sustainable regional economic development. The THM for analysing the evaluation of research and interaction strategies for the advancement of innovation has not been applied before in this specific field. Nevertheless, the THM governance concept could be adapted to the water sector challenges as displayed in Fig. 2.

Taking this into account, five sequential phases were carried out in the study, as depicted in Fig. 3. The first four phases were dedicated to gather background information and the last one was focused on an exercise aiming at a strategic evaluation of water stakeholders capabilities using the SWOT (Strengths, Weaknesses, Opportunities and Threats) technique.

\subsection{Reference and inventory information}

Water stakeholders with expertise and/or interests in water resources management were identified amongst public administration, the research community and businesses, particularly SMEs, from the regions participating in NOVIWAM. Subsequently, an indepth desk study concerning (i) the environmental and socioeconomic frameworks, (ii) the governance and management frameworks, and (iii) existing Research and Development plus Innovation activities (R\&D + I), was carried out. Also, a survey was carried out in which online questionnaires aiming to describe i) water stakeholders, legal and socio-political framework, ii) R\&D + I priority areas, trends, technology and knowledge production and transfer systems, iii) markets, and multi-stakeholder interaction for Decision Support Systems (DSS) in NOVIWAM regions were designed and sent to relevant stakeholders (Fig. 4).

To reinforce this process, interviews with selected stakeholders were conducted to fill knowledge gaps that were identified. A script with the main issues was prepared in advance but the interviews were informal in order to encourage the interviewees to freely express their opinions. A total of 43 interviews (Portugal, 9; Spain, 11; France, 8; Albania, 9; Cyprus, 6) were conducted. The interview 
Table 1

NOVIWAM regions characterization.

\begin{tabular}{|c|c|c|c|c|c|}
\hline & North of Portugal & $\begin{array}{l}\text { Andalusia } \\
\text { (Spain) }\end{array}$ & $\begin{array}{l}\text { Poitou-Charentes } \\
\text { (France) }\end{array}$ & Albania & Cyprus \\
\hline Area $\left(\mathrm{km}^{2}\right)$ & 21278 & 87268 & 25809 & 28748 & 5896 \\
\hline Population ( $10^{6}$ inhabitants) & 3.69 & 8.24 & 1.74 & 3.64 & 0.89 \\
\hline Average annual precipitation ( $\mathrm{mm})$ & $1425^{\mathrm{a}}$ & 550 & 775 & 1485 & 463 \\
\hline Total water demand $\left(\mathrm{Hm}^{3}\right)$ & 2443 & 6140 & 382 & 1311 & 266 \\
\hline Agriculture demand $\left(\mathrm{Hm}^{3}\right)$ & 2126 & 5002 & 206 & 518 & 165 \\
\hline Urban demand $\left(\mathrm{Hm}^{3}\right)$ & 157 & 869 & 149 & 561 & 80 \\
\hline Industrial demand $\left(\mathrm{Hm}^{3}\right)$ & 73 & 200 & 26 & 232 & 21 \\
\hline $\begin{array}{l}\text { Total renewable water resources } \\
\text { per capita }{ }^{\mathrm{b}}\left(\mathrm{m}^{3} / \text { inhabitants/yr) }\right.\end{array}$ & $\begin{array}{l}1700-5000 \\
\text { (security) }\end{array}$ & $\begin{array}{l}1000-1700 \\
\text { (vulnerability) }\end{array}$ & $\begin{array}{l}1700-5000 \\
\text { (security) }\end{array}$ & $\begin{array}{l}>10000 \\
\text { (luxury) }\end{array}$ & $\begin{array}{l}500-1000 \\
\text { (stress) }\end{array}$ \\
\hline Water stress index ${ }^{\mathrm{c}}(\%)$ & 42.9 & 13.2 & 46.6 & - & - \\
\hline
\end{tabular}

a Average between the western (very wet) and eastern (very dry) part of the region.

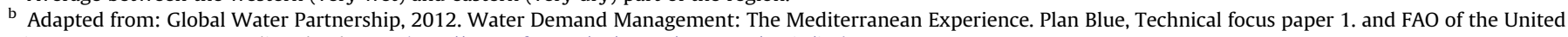
Nations, 2013. AQUASTAT online database, <http://www.fao.org/nr/water/aquastat/main/index.stm >.

${ }^{c}$ Values on a country scale; adapted from: Environmental Performance Index, 2010. Water stress index, <http://www.epi2010.yale.edu/Metrics/WaterStressIndex >.

sample covered different profiles (public authorities, river basin managers, consultants, researchers, educators and stakeholders from other interest groups) and water expertise's identified as relevant to the water sector (water Policy and management, river basin management R\&D + I and development or application of software based DSS used in water management).

\subsection{Strategic analysis}

SWOT stands for Strengths, Weaknesses, Opportunities and Threats, and is a widely used analytical tool to support a strategic analysis (Gallego-Ayala and Juízo, 2011). Nevertheless, a SWOT analysis does not report information about the importance of the topics, so Equation (1) was developed in order to score and weight each topic considering that if it is referred to in more than one region, it is relevant for the global analysis.

$S_{f}=\sum S_{i}=N_{i} / \sum i$

In Equation (1), $S_{f}$ is the final score, $i$ the topic identified in the SWOT, $S_{i}$ the score of each topic, $\sum i$ the sum of all topics in each SWOT category and $N_{i}$ the number of times that each topic was referred in regional SWOT analysis. Using this equation it was possible to compare the importance of each topic.

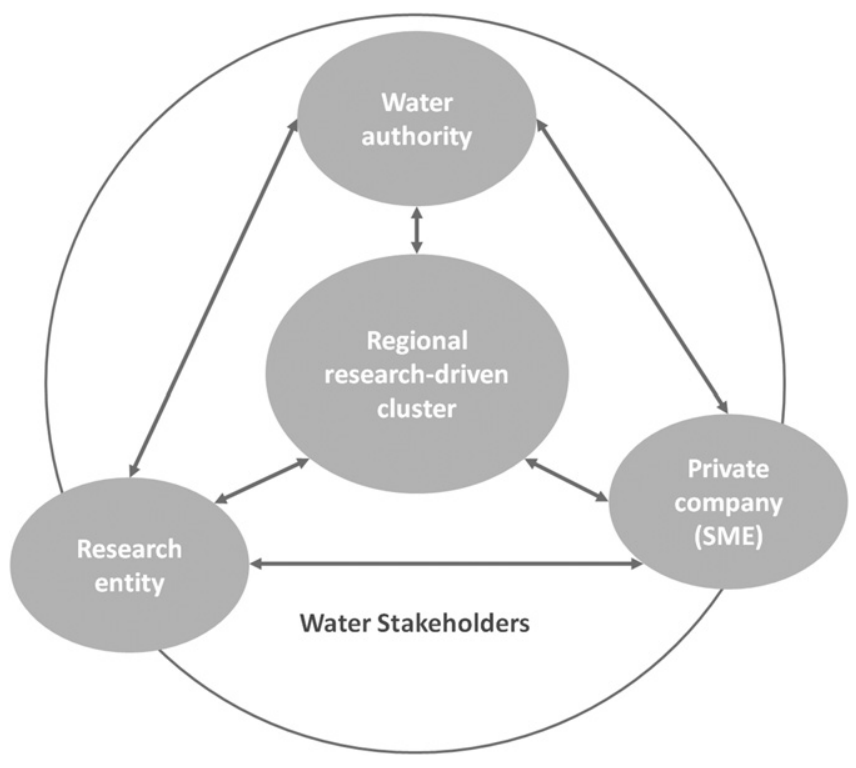

Fig. 2. Triple Helix Model in the water resources sector.
The conclusions extracted from the SWOT analysis, together with different stakeholder consultation sessions, served as a basis for the elaboration of a regional Joint Action Plan (JAP) developed jointly by the NOVIWAM partners. The JAP aims to bring a stronger interaction amongst regional and multinational stakeholders and to foster collective efficiency in water resources management. Moreover, the activities included in the JAP are aimed at solving the weaknesses and mitigating the threats detected in the SWOT by exploiting the existing strengths.

\section{Results}

\subsection{NOVIWAM regions: common problems and shared solutions}

The regions of Northern Portugal (Portugal), Andalusia (Spain) and Poitou-Charentes (France), as well as Albania and Cyprus, are in different positions in terms of WFD application. An example of the current differences is the asymmetries among river basin management plans (RBMP) in EU countries and the new challenges (Blueprint to safeguard Europe's water resources, 2012). From the countries present in the project, France is the one that was most advanced in the planning phase (ended in 2010), while Spain and Cyprus got delayed during the RBMP public consultation process, while Portugal already closed process and RBMP publication is expected soon. The situation in Albania is on a completely different stage as the WFD is not yet mandatory in the country. Such a heterogeneous situation is mainly institutional reasons rather than technological or scientific ones in all of the NOVIWAM regions.

As shown in Fig. 4 the rate of completed online surveys varied among the five clusters. In Portugal, the number of responses account for $16 \%$ of the stakeholders targeted, while in France, Spain, Cyprus and Albania they account for $15 \%, 11 \%, 30 \%$ and $46 \%$, respectively. The different response rates may be due to the different methodologies employed by each cluster in selecting contacted stakeholders. For instance, the Albanian partners addressed their invitations only to their closer contacts, while the Spanish cluster used a different approach and sent invitations to a broader list. Nevertheless, the results from the questionnaires showed that the main interest of stakeholders falls on water policy, water allocation and R\&D + I management. As for the respondents, the majority of Cypriot and Spanish ones were researchers, while French and Albanian participants were mainly river basin managers, in contrast to the Portuguese, which were mostly private entities. In what respects to legal status of the different entities responding, these were mainly public stakeholders in all regions, the exception being Portugal with a similar ratio for respondents from the private and public sectors. 


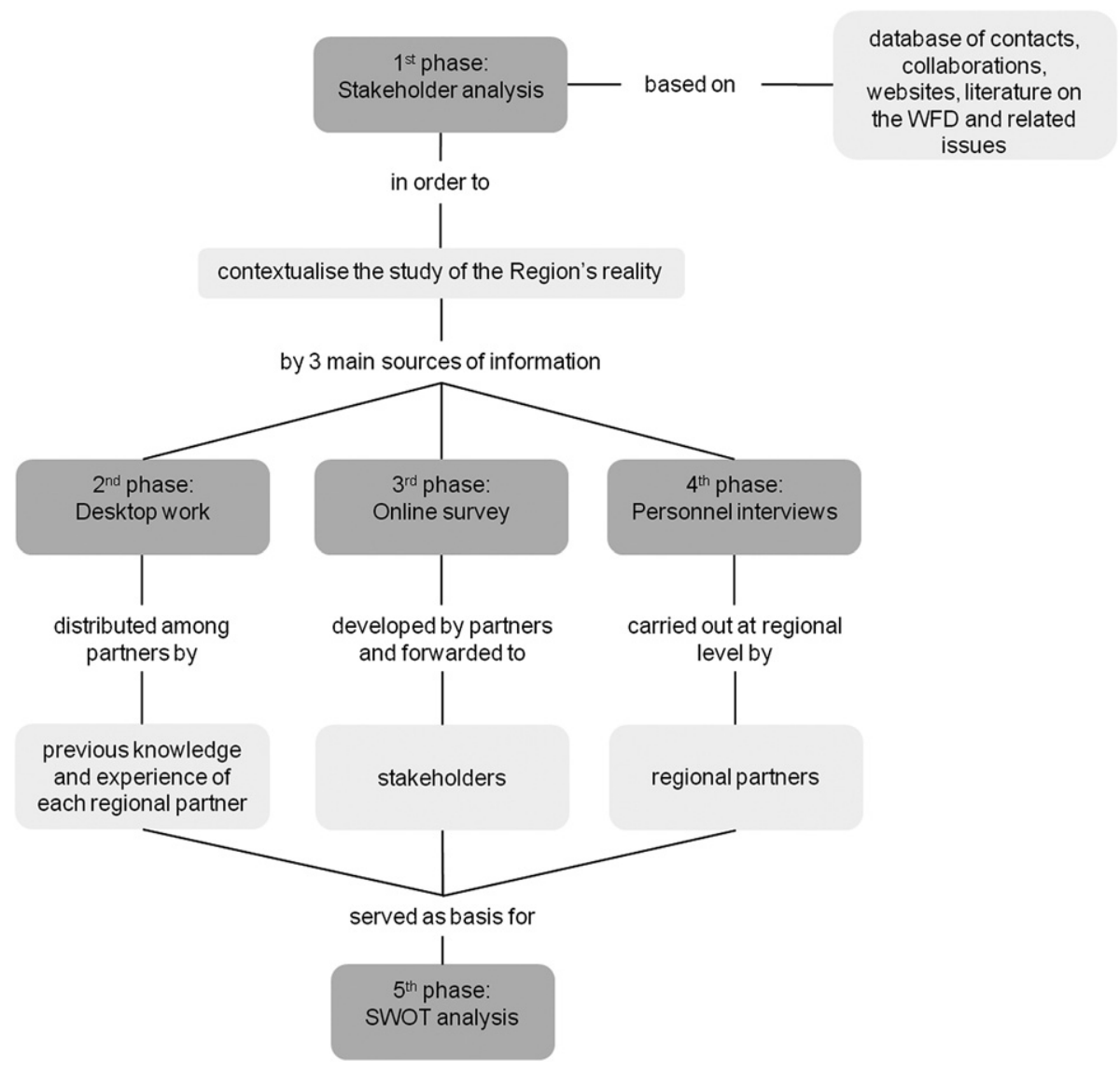

Fig. 3. Methodological work sequence.

Comparing the Gross domestic expenditure on R\&D + I activities in the water sector (2010 data; Eurostat, 2012), it was observed that the average for the 27 member states of European Union amounted to $2.0 \%$ the highest value being observed in Finland 3.9\% (in the NOVIWAM regions these values were $0.2 \%$ in Albania, ${ }^{2} 0.5 \%$ in Cyprus, $1.4 \%$ in Spain, $1.6 \%$ in Portugal and $2.3 \%$ in France). However, the current financial crisis seems to have a negative impact on the fundamental research provided by universities, but the focus on innovation is increasingly important for research centres.

Data on current and priority research areas are depicted in Fig. 5. The questionnaire results identified urban drainage design and analysis, economic analysis, environmental flows and soil erosion and sediment transportation as the areas less developed in NOVIWAM regions. On the other hand, the areas of chemical and ecological status assessment were the most mentioned. Analysing the priority areas, urban drainage design and analysis were selected as priority area by 8 respondents (Fig. 5) but it was not referred as a current research line in any region. Flood risks and droughts, climate change and water and health nexus were the three main areas that researchers point as priorities in the upcoming years.

It is worthwhile to note that the questionnaires and interviews highlighted a significant evolution in NOVIWAM regions in the use of technological tools to support decision-making processes. Andalusia is a clear example of such perspective trend. Based on a sample of 18 research organizations, Fig. 6 presents technological tools that are currently under development or are available to end users.

\footnotetext{
22009 data. “Strategy of Science, Technology and Innovation 2009-2015” (2010), Republic of Albania government.
}

As seen in the figure, several applications of mathematical models and geographical information tools are being developed or used by Andalusian researchers. Other efforts on the development of computerized tools focus on stakeholder consultation processes and methodologies as well as on graphical approach methods. In contrast to the situation in Andalusia, modelling tools for integrated river basin management are not fully operational in Albania.

\subsection{Strategic analysis and SWOT results}

The participating clusters have made a great effort to identify a wide variety of stakeholders and collect a wide range of information. The results showed that the stakeholders are most interested in water policy and management as well as river basin

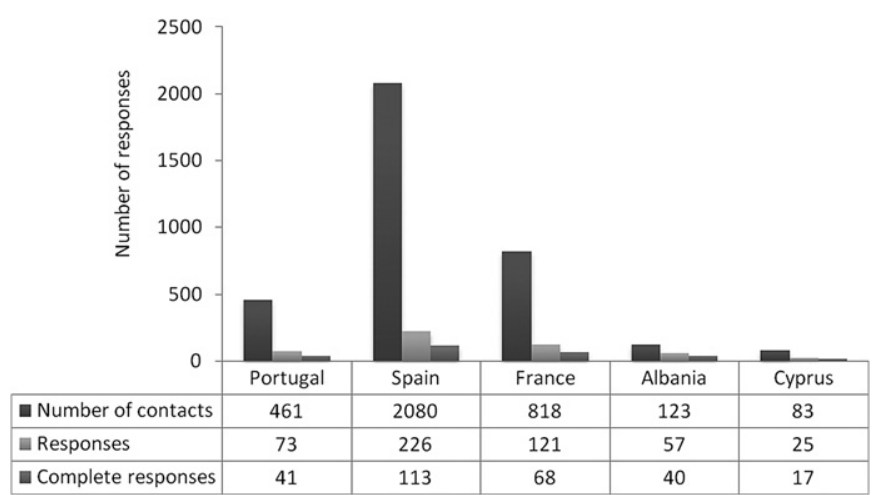

Fig. 4. Number of responses to the survey. 


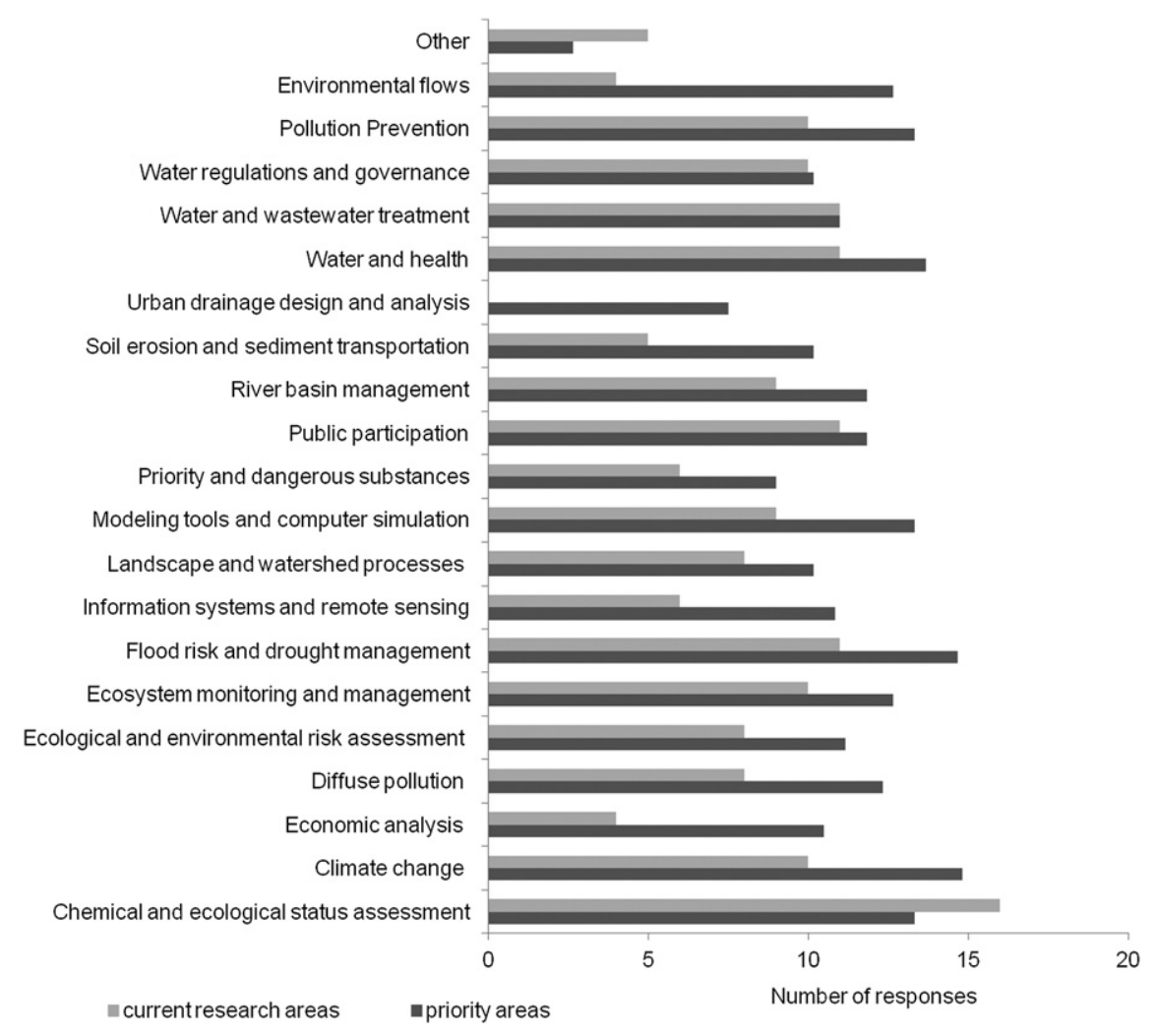

Fig. 5. Current and priority research areas of involvement in NOVIWAM regions.

management R\&D + I activities. Table 2 summarizes the main achievements identified in the SWOT analysis in what refers to research, development and innovation ( $R \& D+I)$ activities.

Regarding the aspects related to R\&D + I, there was a significant evolution detected in the use of technological tools to assist decision-making processes in IRBM in all NOVIWAM regions (Table 2). It is also commonly perceived that the information obtained by computational models will allow decision-makers to make better-informed decisions on water management and planning. The major threat identified is related to the current financial and economical crisis that is limiting the funding available for research in all five regions.

The global SWOT analysis (results not showed) also identified aspects related with the environmental and socio-economic context. The strategic importance of issues related to IWRM, and the implementation of the WFD made related national and EU investments in $R \& D+$ I relatively safe, representing a great opportunity for the triple helix partners in NOVIWAM regions. The difficulties to solve common issues in water and territorial planning, such as over-pumping, diffuse pollution, as well as efficiency issues related to water allocation and pricing was seen as a major

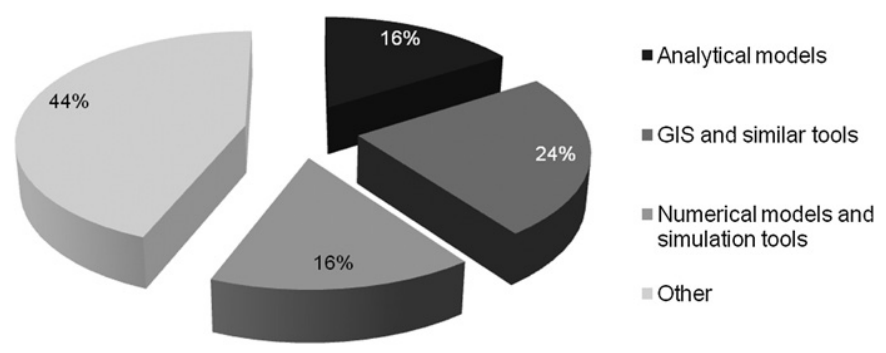

Fig. 6. Technological tools reported by Andalusian researchers. threat. This was worsened by the fact that the level of social awareness on the importance of the environmental aspects of water planning is still low, conditioning the political process and the decisions of managing and planning authorities.

Also, another fact underlined by the institutions participating in NOVIWAM is that concepts such as environmental flows under drought and scarcity, which are critical for the management of water resources in the Mediterranean climate regions (Albania, Cyprus and Andalusia) within the project are not priorities in the WFD, which focuses more on water quality.

Some common key aspects regarding the instruments for water governance and management was the relative novelty of the integrated water management legislation and administrative organization supported by the WFD. When the institutional framework does not comply with the concept of integrated river basin management, tools are adjusted to the necessities of each independent department and complex interactions may not be quantified unless third parties couple or interconnect data from different public bodies. The authorities focused their major concern in the lack of technical and scientific resources, namely technicians and equipment. This impediment seems to slow down the involvement of the administrations' staffs on the use of DSS for river basin management.

The results from the SWOT analysis are depicted in Fig. 7, including all the topics resulting from the global SWOT (a) and related research and development (b).

Analysing the SWOT results using Equation (1), an even distribution between strengths ( $\mathrm{Sf}=4.0$ ), weaknesses ( $\mathrm{Sf}=4.6$ ), opportunities $(\mathrm{Sf}=4.5)$ and threats $(\mathrm{Sf}=4.4)$ can be observed (Fig. 6a). Nevertheless, when we analyse the results of $\mathrm{D} \& \mathrm{D}+\mathrm{I}$ activities only (Fig. $6 \mathrm{~b})$, the weaknesses $(\mathrm{Sf}=2.9$ ) and opportunities $(\mathrm{Sf}=3.5)$ prevail. This analysis also reveals that $80 \%$ of identified opportunities were labelled as research and development issues. 
Table 2

SWOT analysis covering research and development activities.
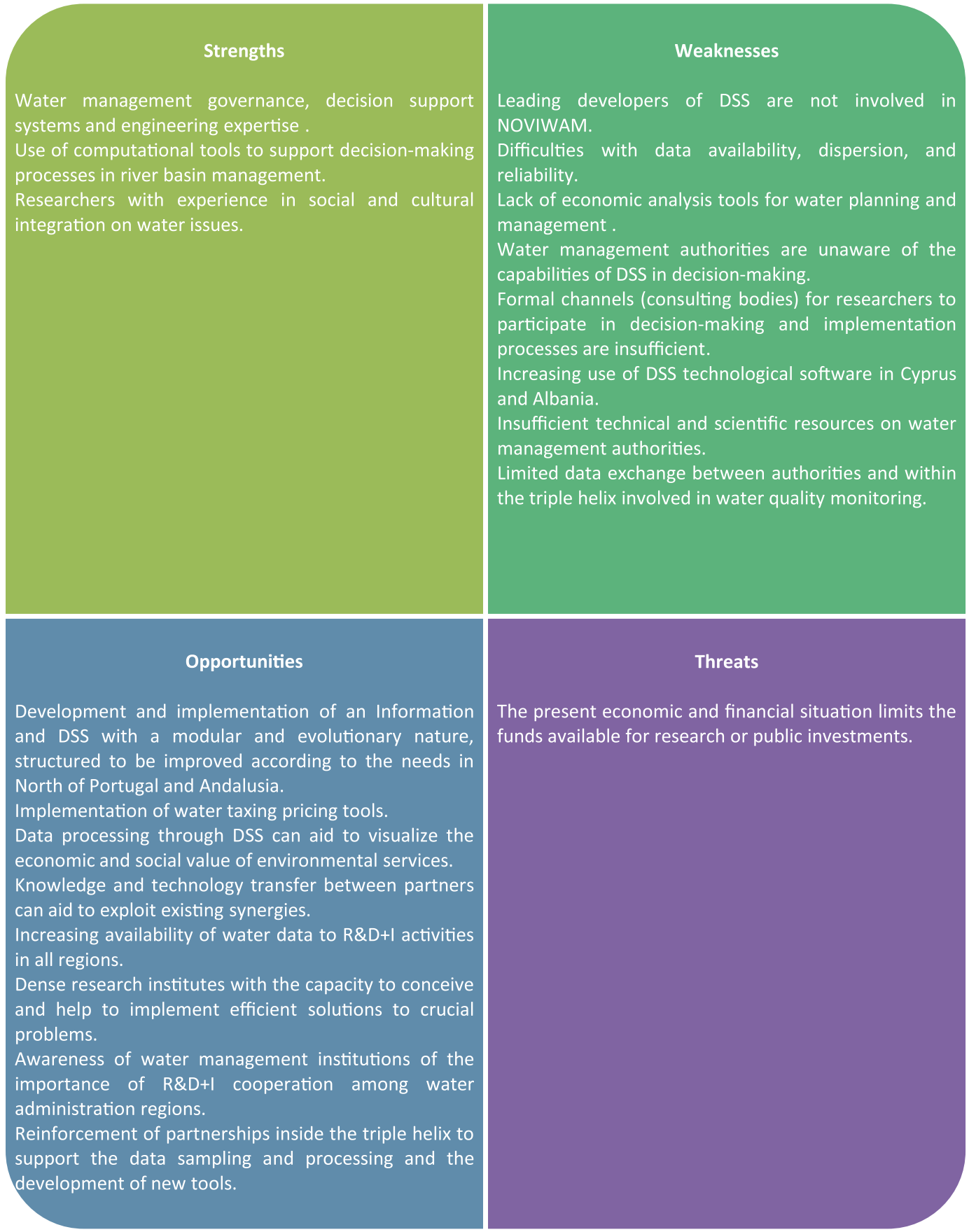

funds available for research or public investments.

\subsection{Joint Action Plan}

The JAP was conceived to prioritize R\&D + I objectives and to promote a collaborative effort for their success. Therefore, two horizontal objectives (HO) have been selected, namely HO1 Bridging links among the triple helix actors, and HO2 - Improving governance and stakeholder capabilities. The first is directed to an interaction focused on practical results because research products are ready to use. The second recognizes that good technology is not

enough and the governance model is really the key factor for efficient water management.

In addition, nine objective areas (scientific objectives - SO) for the JAP were designated, namely SO1) Water bodies status monitoring; SO2) Extreme event risk scenarios; SO3) Groundwater bodies; SO4) Coastal and transitional water bodies; SO5) Interior surface water bodies; SO6) Social and economic value of water; SO7) Optimization of IWRM infrastructures; SO8) Alternative sources of water; SO9) Integration of new technologies. 

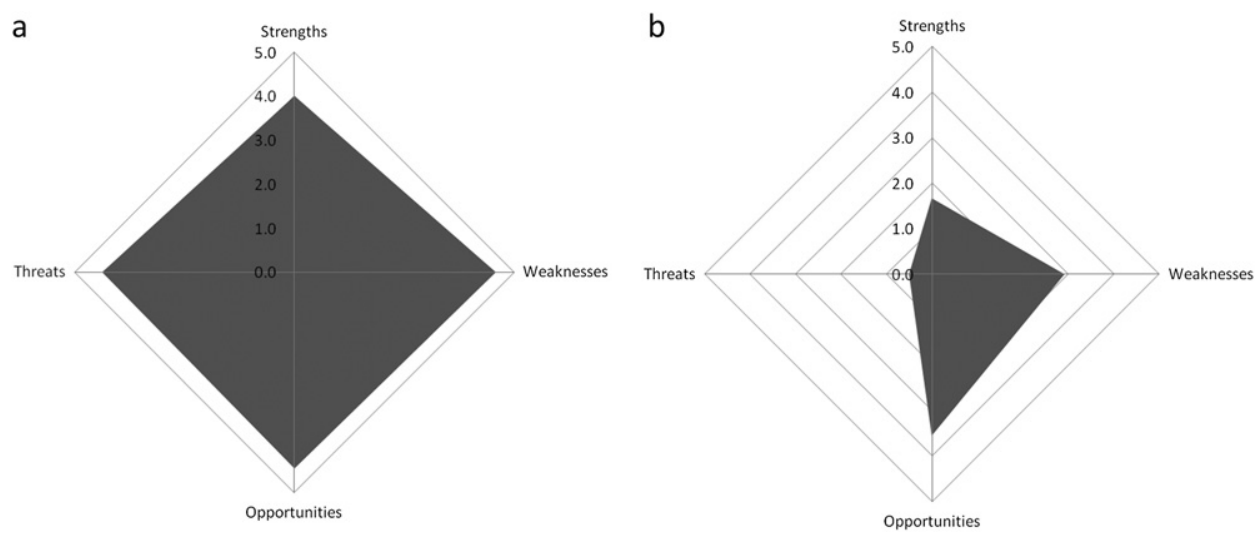

Fig. 7. Graphic representation of results from the SWOT analysis; a) global SWOT; b) research, development and innovation SWOT.

These objectives are related to the necessities detected in the SWOT. They are conceived to ensure that the research and development activities conducted will answer real necessities of the stakeholders and that the results will be easily transferable amongst the triple helix actors.

\section{Discussion}

Water resources management should be reinvented in the actual changing times (Bogardi et al., 2012). Innovation is needed to address water challenges. The combination of the promotion on research and innovation (supply side) together with a strong focus on achieving a shorter time to market innovative products and services (demand side) is needed. A strategic vision and a real operational capacity are both necessary for a transition towards a sustainable water sector. Nevertheless, a strong network is the key for catalysing the process of a southern European water hypercluster. This approach is aligned with the recent European Innovation Partnership on Water launched by EU (EIP, 2012).

The multiobjective nature of water resources challenges motivated the use of evolutionary algorithms for discovering and exploiting the critical tradeoffs facing water resources systems (Reed et al., 2012; Kondili et al., 2010). Advanced water technologies, powerful management tools, monitoring, automation and control systems, as well as improved source control instruments are essential to cope with a demanding integrated water management framework (Reed et al., 2012). In order to allow decisionmakers to take better decisions on water management (Mysiak et al., 2005), in the NOVIWAM regions, there is an increasing use of technological tools to assist decision-making processes in river basin management (e.g. GIS, both hydrological and water quality models). However, a number of managing entities are unaware of the abilities of DSS (particularly numerical modelling) on water resources management decision-making and there are deficiencies in the technical competences of the staff in the river basin management authorities.

In Albania the implementation of a digital database of water usage strengthens the quality of integrated water resources management. Additionally, there have been recent efforts aiming at establishing and strengthening existing R\&D + I activities. In Cyprus, there is a high capacity and commitment among the researchers to the importance of river basin management and flood and drought risk management. In Poitou-Charentes there is a good groundwater monitoring network and online data easily available to the general public. In Andalusia there is increased development of research in the fields of computerized tools, analytical modelling, developments of GIS and applications. In the Northern Portugal several research teams are experienced in the development of DSS and a significant reinforcement of water and wastewater treatment is in progress. It is also important to note the development and implementation of an Information tool and DSS by the management authority with a modular and evolutionary nature, which is structured in a way that can be improved according to the user needs (Northern Portugal).

The opportunities, i.e., the factors of the external environment from which the regional cluster may benefit, are also promising in the NOVIWAM regions. Amongst them are the reinforcement of partnerships between regional water authorities and specialized entities to; increasing availability of water data to be used in $\mathrm{R} \& \mathrm{D}+\mathrm{I}$ (data accessible on the Internet is particularly useful); and to use DSS to process the data and help to visualize the economic value of environmental services.

As for the weaknesses side, there are no advanced economic tools for water management (but its future development is an opportunity) and cases of data availability, data dispersion, data incompatibilities and difficulties to access data were also detected. The results also revealed the absence of formal channels for the exchange of know-how, expertise and relevant data between water authorities, researchers and private entities. This fact hinders the development of joint research projects related to river basin management and the uptaking of their results. One of the reasons is the lack of an active governance system. Open access to information, and meaningful stakeholder participation will improve water management and governance (Haeyer et al., 2011; Bogardi et al., 2012). Indeed, to meet the wide-ranging objectives of good ecological status, water authorities will have to appeal on intensive cooperation among stakeholders (Moss, 2004; Albrecht, 2013).

An approach based on the triple helix concept could guide policy and practice in the process of creating and consolidating knowledgebased regional innovation systems that are practical and useful for society (Etzkowitz and Ranga, 2010). In fact, the application of THM resulted in a closer and more efficient cooperation between NOVIWAM partners. With THM, each part of the helix (public administration, research centres and business companies) bring to the project the best knowledge in each field, what together with the personal contacts, contributed to reach the information in a faster way. Moreover, other study based on formal comparative analyses, concluded that integrated cooperation structures and advanced information management are the key factors leading towards higher levels of policy learning in river basin management (Huntjens et al., 2011).

Stakeholders coming from research centres, universities and private entities emphasized the low availability of data as their major concern, together with the need to advance on research on 
water resource economics. The latter was not surprising, and both are largely discussed at an international level (García-Ruiz et al., 2011; Hoekstra, 2011). However, the fast-paced innovation on information and communication technologies is also facilitating new possibilities for decision-makers to share data and interact with stakeholders and researchers. Several officials pointed that the main difficulty in solving common issues between water and territory results from a well-known deficient interaction between territorial and water planning actors. Inappropriate land occupation, water allocation conflicts or specific problems such as diffuse pollution or water over-abstraction are major threats. All these factors are intensified by water scarcity and floods risks in the Mediterranean countries. A shared perception of land and water values is needed to overcome such problems.

It is very important to stress that many identified opportunities meet identified weakness (Table 2; Fig. 7). The score of all weaknesses (2.9) was overlapped by the score of opportunities (3.5). For instance, it is important to ensure that no weaknesses cancel out strengths and opportunities or region strengths could arise out of correcting weaknesses.

Climate change was considered as a research priority area (Fig. 5) and a global SWOT threat, since it has a wide impact in water resources (Bates et al., 2008; Kampragou et al., 2011). For instance, the future frequency and severity of droughts is recognized as a major issue in the EU, particularly in the Mediterranean region (Kampragou et al., 2011). Indeed, many regions in Mediterranean area (e.g.: Aegean Sea) are addressing many efforts in the research of efficient solution procedures based on large-scale optimization models to an integrated management of desalinated water, wastewater and reclaimed waters (Liu et al., 2012, 2011). Moreover, these procedures should focus on developing new autoadaptive algorithmics that could help to satisfy water demands needs with less costs (Reed et al., 2012). In spite of the importance of water to climate change, some argue that it has been forgotten in the climate debate (Bogardi et al., 2012). In fact, more emphasis is necessary on policy interventions that could encourage the adaptation strategy (Dinar, 2012). In addition, the new RBMP generation that will be presented in 2015 should address this issue, as innovative approaches are needed to sustainably manage the increasing pressures on water resources (EIP, 2012).

The global objective of the NOVIWAM project is to support the cooperation and integration between the research driven clusters in order to increase R\&D + I investments at regional level and optimize their management and use. In this sense, the JAP can work as a guide to address weaknesses and threats and profit from opportunities in each region. At same time, water management authorities can prioritize investments in $\mathrm{R} \& \mathrm{D}+\mathrm{I}$, keeping in mind the costeffectiveness of research needs and management actions (Costa et al., 2009), in line with the EIP on Water, e.g. research and development funding need to be adequately linked to demand side actions, measures and policies which are needed to foster innovations (EIP, 2012). In that regard, a selection of 5 priority research actions under different themes of the JAP was done considering the interest that the authorities participating in NOVIWAM expressed in their results (Fig. 8).

Some opportunities arose from the analysis of the current situation in the NOVIWAN regions. The reinforcement of partnerships between regional water authorities and specialized entities is strategic to support the data production and the development of new tools, mechanisms and technological solutions. The capabilities for knowledge transfer between partners, as well as the significant increase on the availability of tools for data exchange can help exploiting existing synergies and could drive growth and jobs creation. A competitive water sector may increase market uptake but leadership, a joint and collective effort

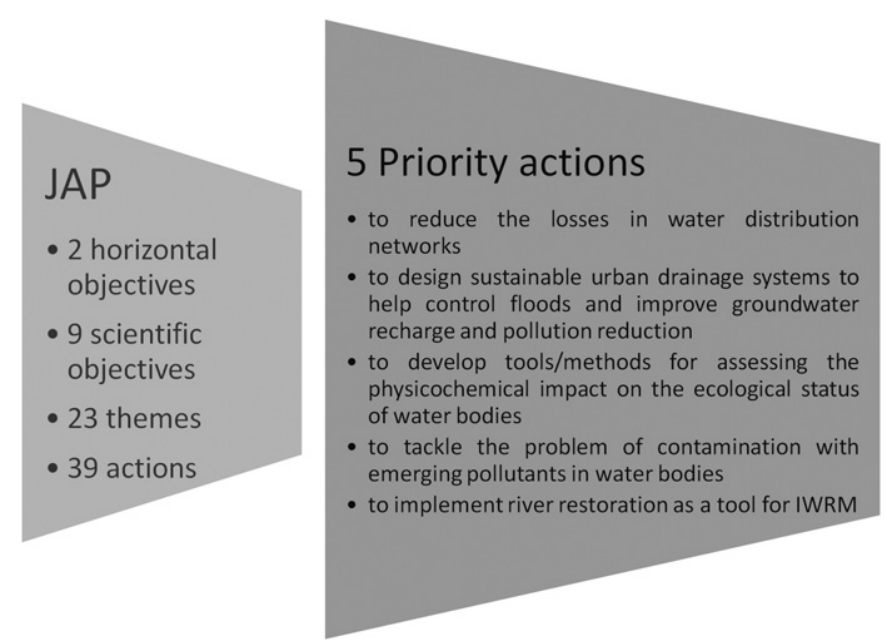

Fig. 8. JAP numbers and description of the 5 priority actions.

and good governance are fundamental pillars. Furthermore, the Horizon 2020, the EU's new programme for research and innovation in Europe, as well as the launch of a European Innovation Partnership on Water, are good prospects for financing an innovative water sector and represent an opportunity for all triple helix partners in the NOVIWAM regions.

\section{Conclusion}

Knowledge and technological tools that may contribute to advancements in water management were identified in NOVIWAN regions and solutions could be driven from the opportunities. Therefore, the main conclusions are the following:

- The THM model is a powerful analytical framework for assessing the efforts of different groups towards a common goal. The gap amongst the triple helix agents is still significant and it does not look like it will be reduced soon;

- A significant evolution in the use of technological tools to assist decision-making processes in integrated river basin management in all the regions;

- The authorities focus their major concern in the lack of technical and scientific resources, mainly of specialized human resources;

- The absence of formal interaction channels between researchers and decision-makers is problematic in water management;

- Researchers and consultants emphasized the low availability of good quality and reliable data as their major concern, together with the need to advance research in water economics;

- The level of social awareness about environmental aspects of water planning is still low and disconnected from the political process;

- The SWOT analysis showed similar concerns amongst different regions and provided a battery of effective (needed) projects that will resulted in a Joint Action Plan.

Finally, it was possible to stress the usefulness and potential of mutual learning between partners and the improvement of their tools to enable their application and adaptation to different realities. A strong interaction framework amongst stakeholders is the best approach to implement the knowledge that already exists in NOVIWAM regions. 


\section{Acknowledgements}

The authors are grateful to all stakeholders that contributed, either by completing the online survey, either by personal interview, as well as to the external evaluators, who contributed to the methodological validation. The authors are also indebted to Alexandrina Rodrigues, Daniel Ribeiro and Teresa Tavares for the manuscript revision. The authors acknowledge NOVIWAM project partners for their valuable comments and contributions, as well as the funding provided by the European Union under the 7th Framework Programme for Research and Technological Development (Grant Agreement $n^{\circ}$ 245460).

\section{References}

Albrecht, J., 2013. The Europeanization of water law by the Water Framework Directive: a second chance for water planning in Germany. Land Use Policy 30, 381-391.

Bates, B.C. (Ed.), 2008. Climate Change and Water. Technical Paper of the Intergovernmental Panel on Climate Change. IPCC, Secretariat, Geneva, p. 210.

Bogardi, J.J., Dudgeon, D., Lawford, R., Flinkerbusch, E., Meyn, A., Pahl-Wostl, C. Vielhauer, K., Vörösmarty, C., 2012. Water security for a planet under pressure: interconnected challenges of a changing world call for sustainable solutions. Current Opinion in Environmental Sustainability 4, 35-43.

Costa, S., Coutinho, L., Brito, A.G., Nogueira, R., Machado, A.P., Salas, J.J., Póvoa, C. 2009. Cost-effectiveness analysis for sustainable wastewater engineering and water resources management: a case study at Minho-Lima river basins (Portugal). Desalination and Water Treatment 4, 22-27.

Cudennec, C., Leduc, C., Koutsoyiannis, D., 2007. Dry land hydrology in Mediterranean regions - a review. Hydrological Sciences Journal 52, 1077-1087.

Dinar, A., 2012. Economy-wide Implications of Direct and Indirect Policy Interventions in the Water Sector: Lessons from Recent Work and Future Research Needs. World Bank Policy Research Working Paper, 6068.

Etzkowitz, H., Ranga, M., 2010. A Triple Helix System for Knowledge-based Regional Development: From "Spheres" to "Spaces". Theme Paper for Triple Helix 8 International Conference, Madrid, October 2010.

European Commission, 2012. Blueprint to safeguard Europe's water resources. http://dx.doi.org/10.2779/60855.

European Community, 2000. Directive 2000/60/EC of October 232000 of the European Parliament and of the Council establishing a framework for community action in the field of water policy. Official Journal of the European Communities L327, 1-72.

European Commission, EIP, 2012. Communication from the Commission to the European Parliament, the Council, the European Economic and Social Committee and the Committee of the Regions on the European Innovation Partnership on Water. COM, Brussels, 216 pp.

Eurostat, 2012. http://epp.eurostat.ec.europa.eu/statistics_explained/index.php/R_\% 26_D_expenditure.

Ferrer, J., Pérez-Martín, M.A., Jiménez, S., Estrela, T., Andreu, J., 2012. GIS-based models for water quantity and quality assessment in the Júcar River Basin, Spain, including climate change effects. Science of the Total Environment 440, 42-59.

Gallego-Ayala, J., Juízo, D., 2011. Strategic implementation of integrated water resources management in Mozambique: an A'WOT analysis. Physics and Chemistry of the Earth. http://dx.doi.org/10.1016/j.pce.2011.07.040.

García-Ruiz, J.M., López-Moreno, J.I., Vicente-Serrano, S.M., Lasanta-Martínez, T., Beguería, S., 2011. Mediterranean water resources in a global change scenario. Earth-Science Reviews 105, 121-139.
Haeyer, T., Knieper, C., Lebel, L., Pahl-Wostl, C. (Eds.), 2011. Synthesis Report Context-sensitive Comparative Analysis of Associations Between Water Governance Properties and Performance in Water Management. Twin2Go Deliverable No. 2.3. Available online: http://www.twin2go.uos.de/downloads/ deliverables/143-d2-3-synthesis-report/download.

Hoekstra, A.Y., 2011. The global dimension of water governance: why the river basin approach is no longer sufficient and why cooperative action at global level is needed. Water 3, 21-46. http://dx.doi.org/10.3390/w3010021.

Huntjens, P., Pahl-Wostl, C., Rihoux, B., Schlüter, M., Flachner, Z., Neto, S Koskova, R., Dickens, C., Kiti, I.N., 2011. Adaptive water management and policy learning in a changing climate: a formal comparative analysis of eight water management regimes in Europe, Africa and Asia. Environmental Policy and Governance 21, 145-163.

Kampragou, E., Apostolaki, S., Manoli, E., Froebrich, J., Assimacopoulos, D., 2011 Towards the harmonization of water-related policies for managing drought risks across the EU. Environmental Science \& Policy 14, 815-824.

Kondili, E., Kaldellis, J.K., Papapostolou, C., 2010. A novel systemic approach to water resources optimisation in areas with limited water resources. Desalination 250, 297-301.

Liu, S., Papageorgiou, L.G., Gikas, P., 2012. Integrated management of nonconventional water resources in anhydrous islands. Water Resources Management 26, 359-375.

Liu, S., Konstantopoulou, F., Gikas, P., Papageorgiou, L.G., 2011. A mixed integer optimisation approach for integrated water resources management. Computers and Chemical Engineering 35, 858-875.

Lopes, E., 2009. Hypercluster da Economia do Mar. In: Sociedade de Avaliação Estratégica e Risco and Associação Comercial de Lisboa (Ed.). Lisboa.

López-Moreno, J.I., Vicente-Serrano, S.M., Morán-Tejeda, E., Lorenzo-Lacruz, J., Kenawy, A., Beniston, M., 2011. Effects of the North Atlantic Oscillation (NAO) on combined temperature and precipitation winter modes in the Mediterranean mountains: observed relationships and projections for the 21st century. Global and Planetary Change 77, 62-76.

Macleod, C.J.A., Scholefield, D., Haygarth, P.M., 2007. Integration for sustainable catchment management. Science of the Total Environment 373, 591-602.

Milly, P.C.D., Dunne, K.A., Vecchia, A.V., 2005. Global pattern of trends in streamflow and water availability in a changing climate. Nature 438 (7066), 347-350.

Miranda, L., Hordijk, M., Molina, R.K.T., 2011. Water Governance Key Approaches: an Analytical Framework. In: Literature Review, Megacities of the Future. LiWa Project.

Moss, T., 2004. The governance of land use in river basins: prospects for overcoming problems of institutional interplay with the EU Water Framework Directive. Land Use Policy 21, 85-94.

Mysiak, J., Giupponi, C., Rosato, P., 2005. Towards the development of a decision support system for water resource management. Environmental Modelling \& Software 20 (2), 203-214.

Pahl-Wostl, C., Holtz, G., Kastens, B., Knieper, C., 2010. Analyzing complex water governance regimes: the management and transition framework. Environmental Science \& Policy 13, 571-581.

Plan Bleu, 2011. Adapting to Climate Change in the Water Sector in the Mediterranean: Situation and Prospects. Plan Bleu, Valbonne (Blue Plan Papers 10).

Reed, P.M., Hadka, D., Herman, J.D., Kasprzyk, J.R., Kollat, J.B., 2012. Evolutionary multiobjective optimization in water resources: the past, present, and future. Advances in Water Resources. http://dx.doi.org/10.1016/j.advwatres.2012.01.005.

Sidibé, Y., Terreaux, J.P., Tidball, M., Fernandez, D., Mayenco, M.U., Berland, J.M., Alcácer-Santos, C., Gjinali, E., Hofstetter, A., Jacquin, N., Kathijotes, N., LuqueRuiz, F.J., Machado, A., Martins, G., Préget, R., Proteriotis, M., Sá, S., Sinojmeri, F., Tapakoudis, M., 2011. NOVIWAM: five European countries together for improving water quality and water use efficiency. In: XIV World Water Congress, September 25-29, Porto de Galinhas, Brazil. 